\title{
Communication
}

\section{Over- and Under-Estimation of Travel Time on Commute Trips: GPS vs. Self-Reporting}

\author{
Carlos Carrion ${ }^{1,+}$ and David Levinson ${ }^{2, *,+(\mathbb{C})}$ \\ 1 College of Computing, Georgia Institute of Technology, Atlanta, GA 30332, USA \\ 2 School of Civil Engineering, University of Sydney, Sydney, NSW 2006, Australia \\ * Correspondence: david.levinson@sydney.edu.au; Tel.: +61-(0)-2-8627-6136 \\ + D.L. conceived of the paper. D.L. and C.C. wrote the paper. C.C. conducted statistical analysis. \\ D.L. edited the paper.
}

Received: 14 June 2019; Accepted: 9 July 2019; Published: 14 July 2019

\begin{abstract}
The underlying structure of road networks (e.g., circuity, relative discontinuity) contributes to the travel time perception of travelers. This study considers additional factors (e.g., arrival flexibility, access to traffic information) and tests nonlinearities linking perception of travel time. These factors are linked to four categories according to time perception research in psychology: temporal relevance, temporal uncertainty, and temporal expectancies; task complexity, absorption, and attentional deployment; and affective elements. This study estimates the relationship on data collected from commuters recruited from a previous GPS-based study in the Minneapolis-St. Paul region consisting of trips from home to work and back. For these work trips, the subjects' self-reported travel times and the subjects' travel times measured by GPS devices were collected. The results indicate that nonlinearities are present for road network attributes. Furthermore, the additional factors (e.g., arrival flexibility, access to traffic information) influence the travel time perception of travelers.
\end{abstract}

Keywords: travel time perception; GPS data; travel behavior; network structure

\section{Introduction}

Travel time is an indispensable characteristic of any transportation system. It is an important pillar that shapes the decisions of travelers (i.e., the demand side) in the transportation market and in an interconnected way, it also influences the decisions of suppliers (e.g., airlines must offer flights that are profitable). Travelers experience travel times. Thus, travelers estimate the travel time through their own cognitive mechanism of perception. This mechanism is the underlying reason behind the mismatch between travel times as reported by a traveler (subjective travel time distribution) and travel times as measured from a device (e.g., loop detector; objective travel time distribution) in collected data.

Subjects' perception of travel times has been found to be a significant factor in numerous studies [1-15]. Travelers overestimate or underestimate the actual travel times they experience, which undoubtedly affects decisions like route choice [16-18]. However, research is just starting to unpack the factors governing the perception error of travelers systematically $[19,20]$.

This study aims to further uncover the factors governing the perception error along with the nonlinearities (e.g., functional forms) linking the perception error and other factors. The studied factors are connected to four categories according to time perception research in psychology: temporal relevance; temporal uncertainty, and temporal expectancies; task complexity, absorption, and attentional deployment; and affective elements. Thus, the underlying context of our research is attempting to place the time perception research conducted in the transportation literature into the 
context of the time perception research conducted in the psychology literature. The methodology is based on regression analysis on data collected (surveys, and Global Positioning System (GPS) points) of commuters recruited from a previous research study by the authors and colleagues in the Minneapolis-St. Paul region [21,22]. The main characteristics of the data are that actual route information is known, the home and work locations of subjects are known, and also subjects filled in several questions regarding their travel experience and their time restrictions (i.e., travelers are allowed to arrive late to work without any reprehension). To avoid confounds, only direct (i.e., no trip chaining) commute trips (from home to work and from work to home) were considered for the analysis. For these work trips, the subjects' self-reported travel times and the subjects' travel times measured by GPS devices were collected. Furthermore, the objective of these previous research efforts was to study the travel behavior of travelers due to the collapse of the I-35W bridge on 1 August 2007 and also after the replacement bridge opened to the public on 18 September 2008. Our goal was to leverage this rich dataset to study factors governing perception error, which have not been previously studied with these data by the authors and colleagues.

The study is organized as follows: a literature review of the relevant research to the topic at hand; hypotheses of the study; materials and methods; statistical models (specification and estimation); and results and discussion.

\section{Literature Review}

The literature review for this study encompasses one main area: travelers' perception of travel time. There are already plenty of studies focusing on this area, and thus, providing a comprehensive review is a difficult task, which is not the purpose of this study. This review presents a selective summary of relevant results of travelers' perception of travel time from the transportation research literature and the psychology research literature. References to further readings are provided for the benefit of the readers.

Psychologists have showed clear interest in the behavioral and cognitive mechanism of the perception of time. They have classified the perception of time into three main categories: subjective time passage (i.e., perception of the speed that time passes); estimation of time duration; and simultaneity and succession of time. The estimation of time duration is the most frequently-studied category by psychologists, and thus, it is better understood. It is also the dimension of time perception that will be the focus of this study, and it has been the focus of most studies investigating the perception of travel time in the transportation literature. The main factors identified for the duration of time are: temporal relevance, temporal uncertainty, affective elements, arousal, task complexity, temporal expectancies, absorption and attentional deployment. Temporal relevance refers to the significance of time for performing a task in an optimal way. Temporal uncertainty refers to how well the subject can estimate the duration of the task given previous experiences. Thus, results indicate that when a task is commonly performed, its uncertainty is low, but when a task is uncommonly performed, its uncertainty is high. In addition, tasks with high levels of relevance and uncertainty are associated with estimates of duration of time tending to be longer. In contrast, tasks with low levels of relevance and uncertainty are associated with a shorter duration of time [23,24]. Affective elements represent the emotional levels of the individuals while performing a task. For example, subjects experiencing fear estimate the duration of time to be shorter than those who are neutral [25-27]. Arousal refers to a state of physical activation. For example, subjects under the influence of drugs may overestimate the duration of time in comparison to others without such influence [28-30]. Task complexity refers to the effort and the characteristics of the task. Research indicates that high complexity leads to overestimation of the duration of time. In general, subjects that process more events during the time at hand will tend to overestimate as they will have more memories [31]. Temporal expectancies refer to the accumulated previous experiences that allow the subject to generate an estimate of the duration of time for a task. Results indicate that previous durations of time will guide the duration of time for a new task (previously performed) and also update experiences [32,33]. Absorption and attentional 
deployment refer to the focus of subjects and their understanding of the task that must be performed. Subjects that do not focus and/or do not understand how to perform the task at hand will take further time figuring the details of it, and thus may overestimate the duration of time $[34,35]$. For more details readers may refer to [36].

In the case of the perception of travel time in the transportation literature, most of the studies as previously mentioned focused on the estimation of time duration of the travelers. In essence, the travel times reported by the travelers are analyzed through several methods with the actual travel times that the subjects experienced. Transportation researchers may have control over the environment similar to psychological researchers through computer-based simulations and/or fixed-base vehicle simulators $[1,2,6]$. On the other hand, transportation researchers may collect data from field observations through questionnaires, cameras, GPS devices, and others $[4,5,37,38]$. It should be noted that there is an obvious trade-off between the analyst's control over the environment and the realism of the environment to the subjects.

In the case of studies using simulators, travelers' preferences towards waiting times during distinct traffic conditions (e.g., free-flow traffic) $[1,2,6]$. They used computer-administered stated choice experiments with written travel times and/or stated choice experiments based on subjects' travel times inside vehicle simulators. The results indicated that subjects' perception of the travel times as presented in the computer-administered experiments and the experiments with vehicle simulators were significantly different. Lastly, the subjects' perception of the travel times was different from the actual travel times of the experiments.

Travelers' perception of their morning commute was studied with field observation [37]. The data sources were reported travel times by subjects from questionnaires and travel times as observed from cameras. The reported travel time distributions were compared to the camera travel time distributions. Travel times for the same commute trips as reported by subjects from questionnaires and travel times as measured from GPS devices have been compared [38] . Both studies found that perception error was relevant. Field measurements of waiting times at transit stations using surveys and cameras were collected by [4,5]. Both studies found that subjects' perceptions of waiting time varied significantly by the environment type (e.g., subjects overestimated waiting times the more the environment was polluted and exposed to traffic), and also, a significant heterogeneity in the variation was found (e.g., women waiting more than $10 \mathrm{~min}$ in perceived insecure environments overestimated dramatically the waiting times).

Underlying structure of road networks contributes to the travel time perception of travelers, as shown with linear regression analysis on the data of two sources: the 2000 Twin Cities Travel Behavior Inventory (TBI); and surveys from the I-35W Bridge collapse and reopening [39,40]. The TBI is a comprehensive one-day house travel survey prepared by the Metropolitan Council and the Minnesota Department of Transportation (Mn/DOT). Participants provide a record of all trips on the surveyed day along with individual and household socio-demographic data [41]. The surveys from the I-35W Bridge collapse and reopening refer to: two hand-out/mail-back paper surveys; one computer-based Internet survey; and GPS data collected from the vehicles of subjects. The purpose of the surveys was to understand the impacts of the bridge collapse and reopening on traveler behavior (see $[18,21,22,42]$ for more details). Furthermore, the factors used in $[39,40]$ were measures based on [43] representing the hierarchical and/or topological features of road networks. Hierarchical attributes should be understood as those characteristics that capture the differentiation (i.e., heterogeneity) that exists in road networks. Topological attributes are those characteristics that identify the distinct connection patterns and connectivity of different configurations of links and nodes of road networks. The factors related to measures of the structure of road networks were statistically significant, and the socio-demographic variables (e.g., income) were not $[39,40]$.

In summary, subjects' perception of travel times has been found to be a significant factor in studies. Travelers overestimate or underestimate the actual travel times they experience. Therefore, this is 
likely to influence their travel decisions. Moreover, only recently, the perception error of travelers has been connected to the structure of road networks.

\section{Hypotheses}

The following hypotheses are based on the previous discussion of factors affecting the time perception of subjects in psychological studies, and their plausibility of similar effectiveness on travelers (more specifically, commuters in this study).

\subsection{Temporal Relevance}

Typical commuters are often bound to workplace time restrictions, and thus may consider choosing an optimal departure time and route as very significant in order to respect these restrictions. Thus, it is plausible that there is a high incentive to not "waste" time during their trip to work.

- Arrival flexibility is a set of four binary variables that represent the subjects' workplace arrival time constraints. The categories are: had to be there at the work start time; may arrive within 20 min of the work start time; may arrive within 60 min of the work start time; may arrive at any time past the work start time. The first category is the base case (source: surveys). Travel time perception could also be a function of late and early arrival penalties regarding the work start time (soft rather than hard constraints), which future research could disentangle.

- $\quad$ Type of trip is a binary variable indicating whether the trip originates from home $(1=$ from home to work) or from work ( $0=$ from work to home) (source: GPS and surveys).

Hypothesis 1. Commuters with significant arrival flexibility will tend to underestimate their travel time, because they are likely to exhibit low temporal relevance. They are allowed to "waste time" during their trip to work. In addition, commuters that are driving from home to work will tend to overestimate their travel time, because they are likely to exhibit high temporal relevance. They are bound by workplace time constraints that may not be found in the work to home trips.

\subsection{Temporal Uncertainty and Temporal Expectancies}

Psychologists define uncertainty dissimilarly to transport researchers. The reason is that in transport networks, there is a high interaction between travelers and also with the elements (e.g., traffic signals, ramp meters) of the transport system. Such an interaction is likely to not be present in the tasks subjects must perform in psychological studies. In commute trips, there is likely to be a link between the temporal expectancy and the temporal uncertainty. The uncertainty of the trip will lead to addition or subtraction of the time elapsed in the trip due to those factors outside of the travelers control, and depending on the magnitude, it is likely that those factors will enter into the memory of travelers. Thus, travelers that expect a trip of $20 \mathrm{~min}$ and experience a trip of $40 \mathrm{~min}$ may tend to expect higher times on the same chosen routes.

- Expected travel time of the trip is the travel time (minutes) a subject indicates as expected to arrive at their destination. This differs from the reported travel times, as those are based on the subject's estimate of the actual travel time of the trip (source: surveys).

- Traffic information is a binary variable indicating whether a subject received any type of pre-trip travel information. 1 = received information; $0=$ did not receive information (source: surveys).

- Trips on Interstate bridges is a binary variable indicating whether a subject crossed the Mississippi River using any of the Interstate bridges (source: GPS).

Hypothesis 2. Commuters with knowledge of traffic from external sources (e.g., radio, TV) will tend to overestimate their travel time, because they are likely to have formed a temporal expectancy (i.e., the received travel conditions) and have accepted a level of temporal uncertainty before initiating their trip. In addition, commuters' trips on bridges on Interstates will tend to underestimate their travel time, because they are likely to 
have high temporal expectancy and also believe these bridges have low temporal uncertainty. Lastly, the expected travel time as indicated by the subjects is also linked to the temporal uncertainty and the temporal expectancy of a trip.

\subsection{Task Complexity and Absorption and Attentional Deployment}

Travelers must experience different changes in the network during their trip. There may be hierarchical discontinuities (e.g., moving from an arterial to a freeway); the network may exhibit circuity (i.e., travelers do not just follow a straight path towards their destination); the distance traveled for the trip in a specific hierarchy (e.g., travelers may travel mostly on freeways); and others. Thus, travelers during their trip are likely to be stimulated by different changes that may require effort on their part to guarantee that they will arrive at the desired destination.

- Relative discontinuity is the sum of changes in street hierarchy (i.e., discontinuity) divided by the trip length. A change in street hierarchy is defined by the change of segment speed (source: GPS).

- Proportion of limited access roads is obtained by diving the trip length of the trip on limited access roads to the total length of the trip (source: GPS).

- Proportion of signalized arterials is obtained by dividing the trip length of the trip on signalized arterials to the total length of the trip (source: GPS). It is unitless.

- Circuity is the ratio of the network distance of a path $P$ to the Euclidean distance of the origin and destination corresponding to the path $P$. This measure captures the inefficiency in the network from a traveler's perspective. It is calculated on the actual commute routes of each trip taken by each subject (source: GPS) It is unitless.

Hypothesis 3. Network measures are likely to be linked to task complexity and absorption and attentional deployment. Traveling through a network may require different degrees of effort on the part of the commuters to keep focused. Thus, commuters traveling on paths requiring more effort should overestimate their travel times. Complexity leads to inaccuracy in general [44,45].

\subsection{Affective Elements}

The emotional value of the trip is also important. Travelers that may find themselves in stressful or unpleasant situations while driving may have their perception of time affected.

- Congestion level represents the subjects' description of their travel experience with regards to the experienced congestion during their trips. The categories are low, medium, and high. The first category is the base case (source: surveys). Future research could provided alternative objective rather than subjective definitions using GPS data vs. free-flow travel time.

- Stress level represents the subjects' description of their travel experience with regards to their stress level during their trips. The categories are low, medium, and high. The first category is the base case (source: surveys).

- Fear of driving on the I-35W bridge and other bridges in the vicinity identifies the subjects that admitted they avoid bridges (including the I-35W bridge, Washington Ave bridge, and 10th Street bridge), because of the fear of bridge collapse (source: surveys).

Hypothesis 4. Congestion levels, stress levels, and fear of bridge collapse are related to the quality of the commute, and thus should be connected to affective elements. If commuters are tired or stressed from the trip, this may have an impact on their perception. Commuters that indicate high levels of congestion in their trips will tend to overestimate their travel time, because it is believed that congested trips are unpleasant to commuters. In addition, commuters that indicate high levels of stress in their trips will tend to overestimate their travel time, because it is believed that stressful trips are unpleasant to commuters. Moreover, commuters that are experiencing fear of bridge collapse are likely to underestimate the travel times, because they are more focused on their own fears rather than the quality of the travel experience. 


\subsection{Socio-Economics and Demographics}

In addition, the models control for two additional variables:

- $\quad$ Gender is a binary variable; $1=$ male; $0=$ female (source: surveys).

- Income is a set of three binary variables: low income ([\$0, $\$ 49,999])$, medium income $([\$ 50,000$, $\$ 99,999])$, and high income $([\$ 100,000, \infty+)])$. The first category is the base case (2008 U.S. dollars) (source: surveys).

Beyond the independent variables, different functional forms were tested. This allows one additional set of hypothesis tests.

Hypothesis 5. Trips that are significantly more complex in comparison to others may lead to even higher perception error. Thus, nonlinearities are hypothesized to be present.

\section{Materials and Methods}

The data used were collected by previous research efforts described in $[18,21,22,42,46]$. The main objective of these past studies was to understand the travel behavior of travelers due to the collapse of the I-35W bridge (1 August 2007) and/or after the replacement for the previously collapsed I-35W bridge opened to the public (18 September 2008) in the Minneapolis-St. Paul region. The data consisted of GPS observations and web-based surveys collected before and after the replacement bridge opened.

This rich dataset was comprised of several observations (i.e., home to work trips, and work to home trips) per subject. There were 64 distinct subjects with complete data used in this analysis drawn from a larger sample whose vehicles were instrumented with GPS units in 2008 prior to the opening of the new I-35W Mississippi River Bridge and who traveled for 8-13 weeks subsequently with the GPS in-vehicle, including after the bridge opening. These 64 subjects, all University of Minnesota staff, were sampled Mondays, Wednesdays, and Fridays about their travel. Data about specific trips were collected on those dates using periodic surveys, and more general data were collected prior to the periodic surveys. We had an average of 13.5 observations per subject, totaling 865 observations. These observations corresponded to the set of home to work trips per subject (514 trips) and the set of work to home trips per subject for the same trips (351 trips) from GPS and survey data per subject. In addition, these work trips (or observations) were trips crossing the Mississippi River using any of the bridges in the Minneapolis-St. Paul region. Details are in [46].

Table 1 summarizes the socio-demographic information of the subjects in the dataset, who differed from the population of the Minneapolis-St. Paul region in several ways: subjects were older, were better educated, a greater proportion were female, and had a more uniform distribution of income.

Table 1. Socio-demographic attributes of the datasets.

\begin{tabular}{llll}
\hline Sample & & Dataset & Census \\
\hline \multirow{2}{*}{ Sex } & Male & $43.93 \%$ & $49.40 \%$ \\
& Female & $56.07 \%$ & $50.60 \%$ \\
\hline Age & (Mean, Std. Deviation) & $(52.38,9.91)$ & $(34.47,20.9)$ \\
\hline \multirow{3}{*}{ Education } & 11th grade or less & $0.00 \%$ & $9.40 \%$ \\
& High School & $18.03 \%$ & $49.60 \%$ \\
& Associate & $22.54 \%$ & $7.70 \%$ \\
& Bachelors' & $51.56 \%$ & $23.20 \%$ \\
& Graduate or Professional & $7.86 \%$ & $10.10 \%$ \\
\hline
\end{tabular}


Table 1. Cont

\begin{tabular}{llll}
\hline Sample & & Dataset & Census \\
\hline & $\$ 49,999$ or less & $15.26 \%$ & $5.20 \%$ \\
Household Income & $\$ 50,000-\$ 74,999$ & 23.47 & $23.30 \%$ \\
& $\$ 75,000-\$ 99,999$ & $36.53 \%$ & $14.60 \%$ \\
& $\$ 100,000-\$ 149,999$ & $21.16 \%$ & $11.00 \%$ \\
& $\$ 150,000$ or more & $3.58 \%$ & $5.90 \%$ \\
\hline \multirow{2}{*}{ Race } & Black/African American & $11.33 \%$ & $6.20 \%$ \\
& White or Caucasian & $81.73 \%$ & $87.70 \%$ \\
& Others & $6.93 \%$ & $6.10 \%$ \\
\hline
\end{tabular}

Minneapolis' Population statistics were obtained from the Census Bureau [47].

Figures 1 and 2 summarize trips according to travel times reported (stated and expected) by the subjects in the periodic surveys and measured through GPS devices on the subjects' vehicles. In general, subjects' stated travel times were greater than measured travel times for trips with travel times less than 20 min. In contrast, subjects' stated travel times were smaller than measured travel times for trips with travel times more than 25 min. Furthermore, subjects' expected travel times were closely similar to measured travel times for trips with travel times less than $15 \mathrm{~min}$. However, subjects expected higher travel times for trips with travel times between $15 \mathrm{~min}$ and $30 \mathrm{~min}$. Lastly, trips with travel times greater than 40 min were always underestimated (both stated and expected) by the subjects. These findings agreed with the law of [48].

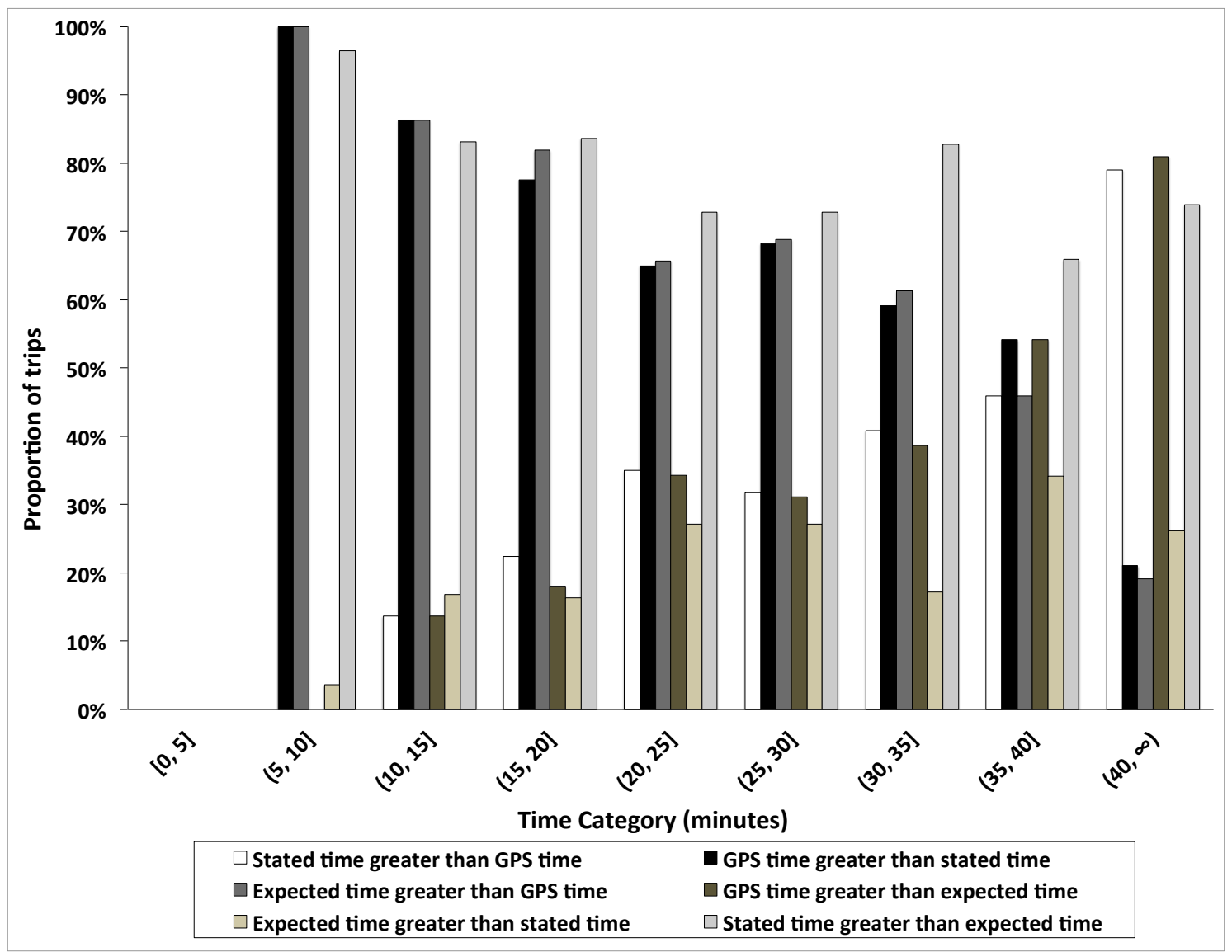

Figure 1. Proportion of trips according to travel time of commute from GPS data and survey data: GPS vs. stated; expected vs. GPS; stated vs. expected. 


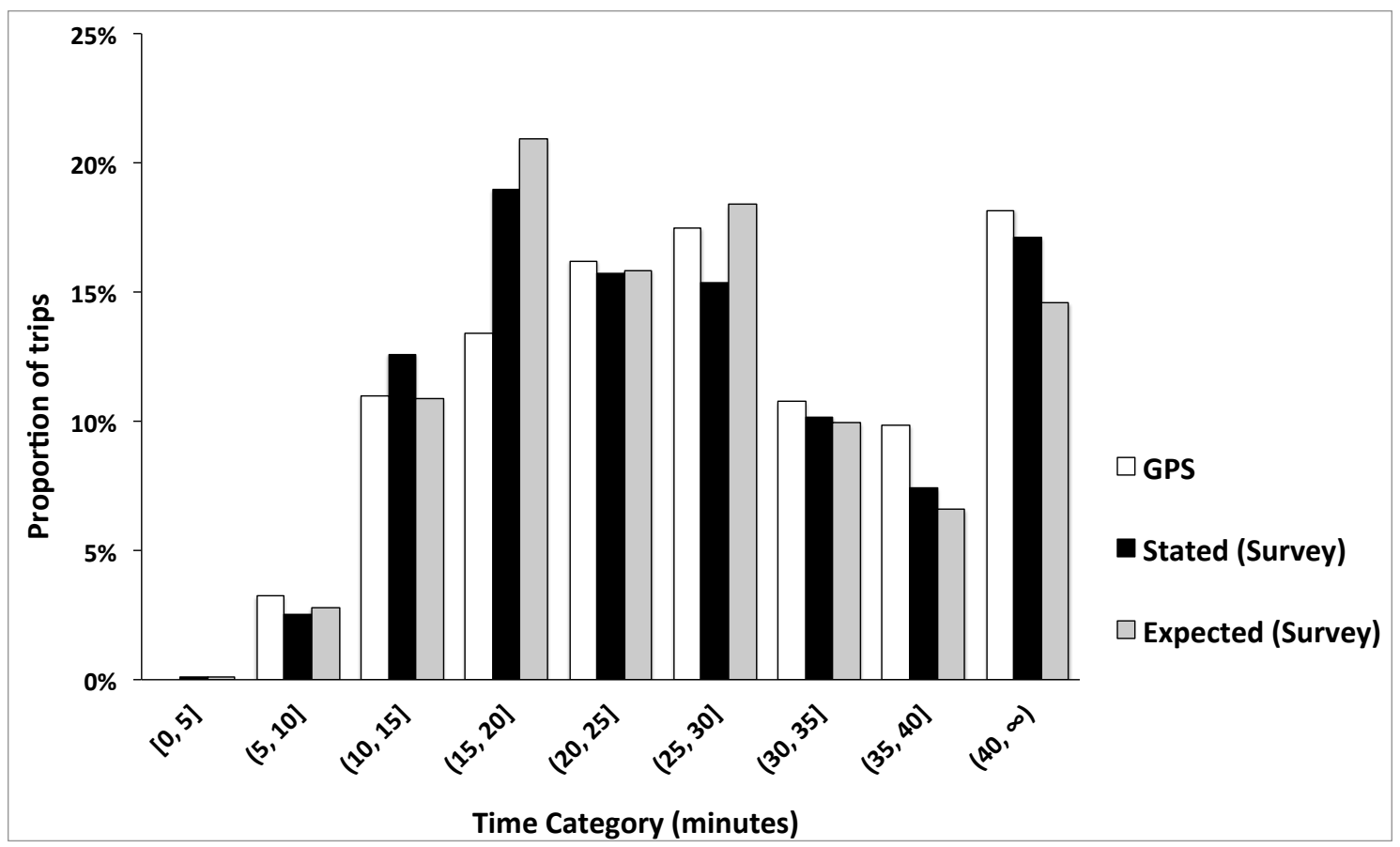

Figure 2. Proportion of trips according to travel time of commute from GPS data and survey data.

\section{Statistical Models}

\subsection{Linear Regression Models}

In the linear regression models, the dependent variable $\left(\tau_{n}^{i}\right)$ was defined as the ratio of reported travel time from surveys $\left(T_{r_{n}}^{i}\right)$ and measured travel time from GPS data $\left(T_{m_{n}}^{i}\right)$. This ratio was calculated for every observation $n$ in the set of observations $\mathcal{N}^{i}$ for subject $i$ and for every subject $i$ in the set of subjects $\mathcal{I}$. This is the exact definition used in $[19,20]$. This ratio is defined mathematically as,

$$
\tau_{n}^{i}=\frac{T_{r_{n}}^{i}}{T_{m_{n}}^{i}}
$$

The general structure of the linear regression models follows the random effects model for panel data [49-52]. This structure is used to handle the correlations due to unobservable variables across observations belonging to the same subject. The $\alpha^{i}$ term captures the correlations (i.e., $\left.\operatorname{Cov}\left(\tau_{n}^{i} \tau_{n^{\prime}}^{i}\right)=E\left(\alpha^{i} \alpha^{i}\right)=\sigma_{\alpha}^{2}\right)$ across observations $\left(n \in \mathcal{N}^{i}\right)$ of the same subject $i$. Mathematically, the general structure is:

$$
\tau_{n}^{i}=f\left(\mathbf{x}_{n}^{i}, \mathbf{z}_{n}^{i} ; \beta\right)+\alpha^{i}+\epsilon_{n}^{i}
$$

The observations (i.e., trips) were divided into two groups: overestimated trips; and underestimated trips. The former refers to trips by subjects with $\tau_{n}^{i}>1$. The latter refers to trips by subjects with $\tau_{n}^{i}<1$. The linear regression models described subsequently were estimated for each of these two groups.

In this study, the Cobb-Douglas functional form (i.e., $\left.\tau_{n}^{i}=f\left(\mathbf{x}_{n}^{i} ; \beta\right)\right)$ was adopted:

$$
\tau_{n}^{i}=\beta_{0} \prod_{j=1}^{h}\left(x_{j n}^{i}\right)^{\beta_{j}} e^{\sum_{j=h+1}^{k} \beta_{j} z_{j n}^{i}}
$$

The likelihood function of the linear regression models is: 


$$
L\left(\beta, \sigma_{\epsilon}^{2}, \sigma_{\alpha}^{2}\right)=\prod_{\forall i \in \mathcal{I}} \int_{-\infty}^{\infty}\left[\prod_{\forall n \in \mathcal{N}^{i}} N\left(\tau_{n}^{i} \mid f\left(\mathbf{x}_{n}^{i}, \mathbf{z}_{n}^{i} ; \beta\right), \sigma_{\epsilon}^{2}, \alpha^{i}\right)\right] N\left(\alpha^{i} \mid 0, \sigma_{\alpha}^{2}\right) d \alpha^{i}
$$

where:

- $\quad f(\cdot)$ : functional forms for the covariates.

- $\tau_{n}^{i}$ : the dependent variable defined in Equation (1).

- $\quad \mathbf{x}_{n}^{i}$ : the vector of continuous covariates described in the Hypotheses Section.

- $\quad \mathbf{z}_{n}^{i}$ : the vector of categorical covariates described in the Hypotheses Section.

- $\quad \beta$ : the vector of parameters to be estimated.

- $\quad \alpha^{i} \sim$ i.i.d. $N\left(0, \sigma_{\alpha}^{2}\right)$ for all $i$.

- $\quad \epsilon_{n}^{i} \sim$ i.i.d. $N\left(0, \sigma_{\epsilon}^{2}\right)$ for all $n$ and $i$.

\subsection{Logistic Regression Model}

In the logistic regression, the dependent variable $\left(\delta_{n}^{i}\right)$ is defined as $\delta_{n}^{i}=1$ if $\tau_{n}^{i}>1$, and $\delta_{n}^{i}=0$ if $\tau_{n}^{i}<1$. $\tau_{n}^{i}>1$ represents the trips (i.e., observations) of subjects that overestimated their travel times. In contrast, $\tau_{n}^{i}<1$ represents the trips (i.e., observations) of subjects that underestimated their travel times. Mathematically, the dependent variable is:

$$
\delta_{n}^{i}= \begin{cases}1, & \text { if } \tau_{n}^{i}>1 \\ 0, & \text { if } \tau_{n}^{i}<1\end{cases}
$$

The general structure of the logistic regression models follows the random effects model for panel data [49-52]. This structure is used to handle the correlations due to unobservable variables across observations belonging to the same subject. Similarly to the linear regression models, the $\alpha^{i}$ term captures the correlations across observations $\left(n \in \mathcal{N}^{i}\right)$ of the same subject $i$. Mathematically, the general structure is:

$$
\operatorname{Prob}\left[\delta_{n}^{i}=1 \mid \mathbf{x}_{n}^{i}, \mathbf{z}_{n}^{i}, \alpha^{i}\right]=\frac{e^{f\left(\mathbf{x}_{n}^{i}, \mathbf{z}_{n}^{i}, \alpha^{i} ; \beta\right)}}{1+e^{f\left(\mathbf{x}_{n}^{i}, \mathbf{z}_{n}^{i}, \alpha^{i} ; \beta\right)}}
$$

The likelihood function of the logistic regression model is:

$$
L\left(\beta, \sigma^{2}\right)=\prod_{\forall i \in \mathcal{I}} \int_{-\infty}^{\infty}\left[\prod_{\forall n \in \mathcal{N}^{i}}\left(\frac{e^{f\left(\mathbf{x}_{n}^{i}, \mathbf{z}_{n}^{i}, \alpha^{i} ; \beta\right)}}{1+e^{f\left(\mathbf{x}_{n}^{i}, \mathbf{z}_{n}^{i}, \alpha^{i} ; \beta\right)}}\right)^{\delta_{n}^{i}}\left(\frac{1}{1+e^{f\left(\mathbf{x}_{n}^{i}, \mathbf{z}_{n}^{i}, \alpha^{i} ; \beta\right)}}\right)^{1-\delta_{n}^{i}}\right] N\left(\alpha^{i} \mid 0, \sigma^{2}\right) d \alpha^{i}
$$

where:

- $\quad f(\cdot)$ : functional forms for the covariates.

- $\quad \delta_{n}^{i}$ : the dependent variable defined in Equation (4).

- $\quad \mathbf{x}_{n}^{i}$ : the vector of continuous covariates described in the Hypotheses Section.

- $\quad \mathbf{z}_{n}^{i}$ : the vector of categorical covariates described in the Hypotheses Section.

- $\beta$ : The vector of parameters to be estimated.

- $\quad \alpha^{i} \sim$ i.i.d. $N\left(0, \sigma^{2}\right)$ for all $i$.

\subsection{Statistical Hypothesis Testing}

There were two hypothesis tests that were considered for the regression models in this study. For the nested models, the Wald tests were used as they only depend on the covariance matrix of the unrestricted models and do not require estimation of the restricted models. These tests are asymptotically equivalent to the likelihood ratio tests. See [51-53] for more details. 


\subsection{Statistical Estimation}

The linear regression models and the logistic regression model were estimated using maximum likelihood methods [53]. Both set of models follow the random effects model for panel data [49-52]. The estimation of the models was done by maximizing their respective log likelihood functions. For the linear regression models, the likelihood function was of closed form. For the logistic regression model, numerical integration (adaptive Gauss-Hermite quadrature; 30 integration points) was used as the likelihood function was not of closed form.

\section{Results}

Table 2 presents the estimates of the regression models. The first hypothesis was centered on temporal relevance. It concerned two sets of variables: arrival flexibility; and type of trip. The variables representing arrival flexibility were statistically significant by at least $5 \%$ in the linear regression models for trips with travel times underestimated. Commute trips (with travel times underestimated) of subjects with higher arrival flexibility to work were more likely to further underestimate their travel time in comparison to other commute trips (with travel times underestimated) of subjects. However, it was not statistically significant in the other models, but not contradicted. The variable representing type of trip (home to work and work to home) was not found to be statistically significant in any of the models.

The second hypothesis was centered on temporal uncertainty and temporal expectancy. It concerned three sets of variables: traffic information; trips on Interstate bridges; and expected travel time of the trip. The variable representing traffic information was only statistically significant by at least $10 \%$ in the linear regression models for trips with travel times overestimated and the logistic regression models. This result corroborated the second hypothesis up to a point. Usage of traffic information influenced the subjects' ability to estimate the travel time of their trips; however, its effect was not statistically significant by at least $10 \%$ in most models, and its effect may further increase or decrease the overestimation of trips depending on the information provided. For example, subjects receiving average travel times may believe their travel time to be shorter or longer when the actual travel times are lower or higher with respect to the average travel times. Thus, traffic information as a variable influencing travel time perception requires further study. The variable representing trips on Interstate bridges was only statistically significant by at least $5 \%$ in the linear regression models for trips with travel times underestimated and the logistic regression models. These results agreed with the second hypothesis that commuters' trips on bridges on Interstates will tend to underestimate their travel. Furthermore, the presence of the expected travel time of their trips as indicated by the subjects was statistically significant by at least $5 \%$ in all models. The direction of the expected travel time variable must be interpreted carefully. It must be remembered that subjects' expectation of travel time may be influenced by unknown variables including but not limited to: past experiences; and presence of anchors (e.g., signals that provide confidence in an uncertain environment).

The third hypothesis was centered on task complexity and absorption and attentional deployment. It concerned four sets of variables: relative discontinuity; proportion of limited access roads; proportion of signalized arterials; and circuity. Relative discontinuity was statistically significant at the $5 \%$ level or better in at least one of the three models, and not contradicted in the others. It was associated with lower reported travel time, relative to the observed. Circuity and proportion of signalized arterials were both associated with higher reported travel time relative to the observed, which was consistent with the hypothesis, though with a diminishing effect in the logistic regression. However, the proportion of limited access roads was found not to be statistically significant. These results corroborated the third hypothesis. In addition, these results agreed with previous findings by $[39,40]$ and further extended their work by considering the nonlinearities in the relationships of these regressors and the perception of travel time. 
Table 2. Regression models.

\begin{tabular}{|c|c|c|c|c|c|c|c|c|c|c|}
\hline \multirow[b]{3}{*}{ Hyp } & \multirow[b]{3}{*}{ Variable } & \multicolumn{6}{|c|}{ Cobb-Douglas $\left(\tau_{n}^{i}\right)$ (Equation (1)) } & \multirow{2}{*}{\multicolumn{3}{|c|}{ Logistic $\left(\delta_{n}^{i}\right)$ (Equation (4)) }} \\
\hline & & \multicolumn{3}{|c|}{ Underestimated } & \multicolumn{3}{|c|}{ Overestimated } & & & \\
\hline & & Coef. & (T-Stats) & Sig. & Coef. & (T-Stats) & Sig. & Coef. & (T-Stats) & Sig. \\
\hline \multicolumn{11}{|c|}{ Temporal Relevance } \\
\hline $\mathrm{U}$ & $\begin{array}{l}\text { Arrival flexibility: } \\
\text { Within } 20 \text { min of start time } \\
(1=\text { In; } 0=\text { Out })\end{array}$ & -0.025 & $(-0.74)$ & & 0.059 & $(1.07)$ & & 0.096 & $(0.29)$ & \\
\hline $\mathrm{U}$ & $\begin{array}{l}\text { Arrival flexibility: } \\
\text { Within } 60 \text { min of start time } \\
(1=\text { In; } 0=\text { Out })\end{array}$ & -0.064 & $(-1.58)$ & & 0.061 & $(1.00)$ & & 0.33 & $(0.83)$ & \\
\hline U & $\begin{array}{l}\text { Arrival flexibility: } \\
\text { At any time beyond start time } \\
(1=\operatorname{In} ; 0=\text { Out })\end{array}$ & -0.095 & $(-2.53)$ & ** & -0.0056 & $(-0.09)$ & & -0.040 & $(-0.11)$ & \\
\hline $\mathrm{O}$ & $\begin{array}{l}\text { Type of trip } \\
(1=\text { from home to work; } \\
0=\text { from work to home })\end{array}$ & -0.00095 & $(-0.04)$ & & -0.049 & $(-1.24)$ & & 0.35 & (1.49) & \\
\hline \multicolumn{11}{|c|}{ Temporal Uncertainty and Temporal Expectancies } \\
\hline $\mathrm{U}$ & Expected travel time & & & & & & & -0.134 & $(-6.53)$ & $* * *$ \\
\hline $\mathrm{U}$ & Expected travel time ${ }^{2}$ & -0.59 & $(-15.37)$ & $* * *$ & -0.56 & $(-8.96)$ & $* * *$ & & & \\
\hline o & $\begin{array}{l}\text { Traffic information } \\
(1=\text { received } 0=\text { otherwise })\end{array}$ & -0.024 & $(-0.58)$ & & -0.10 & $(-1.88)$ & * & 0.65 & $(1.84)$ & * \\
\hline $\mathrm{U}$ & $\begin{array}{l}\text { Interstate bridge } \\
(1=\text { used; } 0=\text { otherwise })\end{array}$ & -0.070 & $(-3.12)$ & ** & -0.049 & $(-1.41)$ & & -0.59 & $(-2.70)$ & ** \\
\hline \multicolumn{11}{|c|}{ Task Complexity and Absorption and Attentional Deployment } \\
\hline $\mathrm{O}$ & Relative discontinuity & & & & & & & 0.33 & (1.18) & \\
\hline $\mathrm{O}$ & Relative discontinuity ${ }^{2}$ & -0.054 & $(-2.25)$ & ** & -0.09 & $(-2.59)$ & ** & & & \\
\hline $\mathrm{U}$ & Proportion of limited access roads & & & & & & & -1.53 & $(-1.62)$ & \\
\hline $\mathrm{U}$ & Proportion of limited access roads ${ }^{2}$ & 0.0058 & $(0.48)$ & & 0.0018 & $(0.10)$ & & & & \\
\hline o & Proportion of signalized arterials & & & & & & & 9.06 & (2.56) & ** \\
\hline $\mathrm{O}$ & Proportion of signalized arterials ${ }^{2}$ & 0.073 & (3.44) & ** & 0.11 & (3.20) & $* *$ & -10.54 & $(-1.76)$ & * \\
\hline $\mathrm{O}$ & Circuity & & & & & & & 4.86 & (3.28) & ** \\
\hline $\mathbf{O}$ & Circuity $^{2}$ & 0.076 & $(0.84)$ & & 0.67 & $(5.72)$ & $* * *$ & -0.55 & $(-2.44)$ & ** \\
\hline
\end{tabular}


Table 2. Cont.

\begin{tabular}{|c|c|c|c|c|c|c|c|c|c|c|}
\hline \multirow[b]{3}{*}{ Hyp } & \multirow[b]{3}{*}{ Variable } & \multicolumn{6}{|c|}{ Cobb-Douglas $\left(\tau_{n}^{i}\right)$ (Equation (1)) } & \multirow{2}{*}{\multicolumn{3}{|c|}{ Logistic $\left(\delta_{n}^{i}\right)$ (Equation (4)) }} \\
\hline & & \multicolumn{3}{|c|}{ Underestimated } & \multicolumn{3}{|c|}{ Overestimated } & & & \\
\hline & & Coef. & (T-Stats) & Sig. & Coef. & (T-Stats) & Sig. & Coef. & (T-Stats) & Sig. \\
\hline \multicolumn{11}{|c|}{ Affective Elements } \\
\hline $\mathbf{O}$ & $\begin{array}{l}\text { Medium congestion level } \\
(1=\mathrm{In} ; 0=\text { Out })\end{array}$ & -0.055 & $(-1.94)$ & & 0.0041 & $(0.08)$ & & -0.73 & $(-2.39)$ & ** \\
\hline $\mathbf{O}$ & $\begin{array}{l}\text { High congestion level } \\
(1=\mathrm{In} ; 0=\text { Out })\end{array}$ & -0.27 & $(-5.13)$ & & 0.031 & $(0.24)$ & & -1.96 & $(-3.09)$ & ** \\
\hline $\mathrm{O}$ & $\begin{array}{l}\text { Medium stress level } \\
(1=\mathrm{In} ; 0=\text { Out })\end{array}$ & -0.040 & $(-1.41)$ & & -0.0112 & $(-0.20)$ & & -0.105 & $(-0.32)$ & \\
\hline $\mathrm{O}$ & $\begin{array}{l}\text { High stress level } \\
(1=\mathrm{In} ; 0=\text { Out })\end{array}$ & -0.17 & $(-2.29)$ & $* *$ & -0.21 & $(-1.54)$ & & 0.589 & $(0.73)$ & \\
\hline $\mathrm{U}$ & $\begin{array}{l}\text { Fear of bridges } \\
(1=\mathrm{In} ; 0=\text { Out })\end{array}$ & 0.097 & $(1.35)$ & & -0.015 & $(-0.18)$ & & -0.37 & $(-0.68)$ & \\
\hline \multicolumn{11}{|c|}{ Socioeconomics and Demographics } \\
\hline & $\begin{array}{l}\text { Gender } \\
{[1=\text { Male; } 0=\text { Female }]}\end{array}$ & -0.022 & $(-0.32)$ & & -0.05 & $(-0.62)$ & & -0.42 & $(-0.79)$ & \\
\hline & $\begin{array}{l}\text { Income } \\
{[\$ 50,000, \$ 99,999]} \\
(1=\mathrm{In} ; 0=\text { Out })\end{array}$ & 0.073 & $(0.75)$ & & $(-0.076)$ & $(-0.59)$ & & 0.84 & $(1.07)$ & \\
\hline & $\begin{array}{l}\text { Income } \\
{[\$ 100,000, \infty+)} \\
(1=\text { In; } 0=\text { Out })\end{array}$ & 0.11 & $(1.02)$ & & -0.0086 & $(-0.06)$ & & 1.42 & (1.66) & \\
\hline & Intercept/scale constant & 1.81 & $(11.05)$ & $* * *$ & 2.13 & $(8.66)$ & $* * *$ & 03.37 & $(-1.85)$ & * \\
\hline & Dispersion parameter $\left(\sigma_{\epsilon}\right)$ & 0.19 & (30.15) & $* * *$ & 0.25 & (22.58) & $* * *$ & & & \\
\hline & Random effect $\left(\sigma_{\alpha}, \sigma\right)$ & 0.24 & $(8.66)$ & $* * *$ & 0.28 & $(7.42)$ & $* * *$ & 1.76 & $(6.07)$ & *** \\
\hline & Intercept log likelihood $\Pi_{A} S C$ & -87.790 & & & -130.1009 & & & -578.31024 & & \\
\hline & Final $\log$ likelihood $l l_{\hat{\beta}}$ & 49.254 & & & -67.8643 & & & -440.6271 & & \\
\hline & Likelihood ratio index $\rho^{2}$ & & & & & & & 0.23807827 & & \\
\hline & Akaike Information Criterion (AIC) & -54.50895 & & & 179.7286 & & & 927.2543 & & \\
\hline & Bayesian Information Criterion (BIC) & 129.074 & & & 263.7704 & & & 1036.797 & & \\
\hline & Number of observations & 528 & & & 337 & & & 865 & & \\
\hline & Number of subjects & 60 & & & 60 & & & 64 & & \\
\hline
\end{tabular}

Note: * indicates $10 \%$ significance level, ${ }^{* *} 5 \%$ significance level, ${ }^{* * *} 1 \%$ significance level. Bold hypothesis indicates corroborated. Italic hypothesis indicates refuted. Otherwise, the test of the hypothesis was not statistically significant. 
The fourth hypothesis was centered on affective elements. It concerned three sets of variables: congestion levels; stress levels; and fear of driving on bridges due to a previous bridge collapse. In general, the results were mixed with regards to corroborating the fourth hypothesis. Congestion levels and stress levels were statistically significant by at least $10 \%$, but high levels of these variables led to underestimation of travel times in commute trips. Thus, the question was what the subjects understood by congestion levels and by stress levels in the periodic surveys. It is unknown whether the subjects' understanding of the abstract situation matched the authors' intention (i.e., high congestion levels and high stress levels are unpleasant) of the abstract situation. Subjects may tolerate high congestion levels in their trips, because of their continuous recurrence. Similarly, subjects may tolerate high stress levels in their trips, because of their continuous recurrence. In addition, subjects' attitudes (e.g., optimism) toward congestion levels and stress levels may dominate. These variables require further research and more specific questions to isolate their effects.

The fifth hypothesis was centered on the presence of nonlinearities. The results indicated that nonlinearities were present. Wald statistical tests indicated that the nonlinearities of the variables representing task complexity and absorption and attentional deployment were jointly statistically significant at $5 \%$. In general terms, trips that were significantly more complex in comparison to others may lead to even higher perception error.

Reported travel time tended to have rounding errors, and it was not clear whether the reported time was actually the perceived travel time or whether people were intentionally exaggerating; for instance, the work in [3] found that reporting errors of travel times cannot be attributed to (behaviorally-relevant) misperceptions.

Lastly, the variables representing random effects were statistically significant at $1 \%$ in all the models. This indicates that there were unobservable variables (i.e., unobserved heterogeneity) attributed to each subject influencing his/her own perception of travel time in his/her trips.

\section{Discussion and Concluding Remarks}

Recent research $[39,40]$ identified a set of factors describing the underlying structure of road networks as contributors to the travel time perception of travelers. The factors used in $[39,40]$ were measures based on [43] representing the hierarchical and/or topological features of road networks. Hierarchical attributes should be understood as those characteristics that capture the differentiation (i.e., heterogeneity) that exists in road networks. Topological attributes are those characteristics that identify the distinct connection patterns and connectivity of different configurations of links and nodes of road networks. Similarly, our study further explored factors belonging to four categories according to time perception research in psychology: temporal relevance (arrival flexibility and type of trip); temporal uncertainty and temporal expectancies (traffic information, trips on Interstate bridges, and expected travel times of trips); task complexity and absorption and attentional deployment (relative discontinuity, proportion of limited access roads, proportion of signalized arterials, and circuity); and affective elements (congestion levels, stress levels, and fear of driving on bridges). We studied the influence of these factors on travel time perception by leveraging a rich dataset collected from commuters recruited for a previous research study in the Minneapolis-St. Paul region [18,21,22,42]. These data (surveys, and Global Positioning System points) consisted of work trips (from home to work, and from work to home) of subjects. For these work trips, the subjects' self-reported travel times, and the subjects' travel times measured by GPS devices were collected. Briefly, the statistical results were consistent with the hypotheses and were statistically significant at the $5 \%$ level or better in at least one of the three models, and not contradicted in the others. However, the factors related to affective elements require further research to isolate their effects on time perception. Furthermore, a departure from previous studies was our effort to make more explicit the underlying context of our research conducted in the transportation literature in the context of the time perception research in the psychology literature. Thus, we sought to leverage the accumulated knowledge of time perception in psychology to further understand and characterize our results. 
These results continue to highlight the need to further study the perception of travel time and to acknowledge its influence on travelers' decisions. Thus, the modeling of travel decisions must account for perception error. This is an important research topic as many analyses (e.g., economic, planning) and models (e.g., economic, traffic) in transport continue to ignore that travelers are executing decisions according to their own divergent views of the actual travel time distributions.

Future research should increasingly continue to explore the incorporation of these empirical travel time perception functions into the modeling of travel decisions in order to increase the realism and insights obtained from transport economic and planning models. Fortunately, this nascent strand of research is gaining momentum in the transportation research literature. An early example is [9]; they took into account perception error in the development of a travel mode choice model and found among other results that it generated more realistic estimates for willingness to pay measures for travel time savings.

Author Contributions: D.L. conceived of the paper. D.L. and C.C. wrote the paper. C.C. conducted the statistical analysis. D.L. edited the paper.

Funding: This research was funded by the Oregon Transportation Research and Education Consortium (2008-130 Value of Reliability and 2009-248 Value of Reliability Phase II) and the Minnesota Department of Transportation project "Traffic Flow and Road User Impacts of the Collapse of the I-35W Bridge over the Mississippi River".

Acknowledgments: We would also like to thank Shanjiang Zhu, Kathleen Harder, and the late John Bloomfield.

Conflicts of Interest: The authors declare no conflict of interest.

\section{References}

1. Levinson, D.; Harder, K.; Bloomfield, J.; Carlson, K. Waiting Tolerance: Ramp Delay vs. Freeway Congestion. Transp. Res. Part F Traffic Psychol. Behav. 2006, 9, 1-13. [CrossRef]

2. Levinson, D.; Harder, K.; Bloomfield, J.; Winiarczyk, K. Weighting Waiting: Evaluating the Perception of In-Vehicle Travel Time Under Moving and Stopped Conditions. Transp. Res. Rec. J. Transp. Res. Board 2004, 1898, 61-68. [CrossRef]

3. Peer, S.; Knockaert, J.; Koster, P.; Verhoef, E.T. Over-reporting vs. overreacting: Commuters' perceptions of travel times. Transp. Res. Part A Policy Pract. 2014, 69, 476-494. [CrossRef]

4. Lagune-Reutler, M.; Guthrie, A.; Fan, Y.; Levinson, D.M. Transit Riders' Perception of Waiting Time and Stops' Surrounding Environments; Transportation Research Board: Washington, DC, USA, 2016.

5. Fan, Y.; Guthrie, A.; Levinson, D. Waiting time perceptions at transit stops and stations: Effects of basic amenities, gender, and security. Transp. Res. Part A Policy Pract. 2016, 88, 251-264. [CrossRef]

6. Wu, X.; Levinson, D.; Liu, H. Perception of waiting time at signalized intersections. Transp. Res. Rec. J. Transp. Res. Board 2009, 2135, 52-59. [CrossRef]

7. Zhang, L.; Xie, F.; Levinson, D. Illusion of motion: Variation in value of travel time under different freeway driving conditions. Transp. Res. Rec. J. Transp. Res. Board 2009, 2135, 34-42. [CrossRef]

8. Ribeiro, M.D.; Larrañaga, A.M.; Arellana, J.; Cybis, H.B. Influence of GPS and self-reported data in travel demand models. Procedia -Soc. Behav. Sci. 2014, 162, 467-476. [CrossRef]

9. Varotto, S.F.; Glerum, A.; Stathopoulos, A.; Bierlaire, M.; Longo, G. Mitigating the impact of errors in travel time reporting on mode choice modelling. J. Transp. Geogr. 2017, 62, 236-246. [CrossRef]

10. Varela, J.M.L.; Börjesson, M.; Daly, A. Quantifying errors in travel time and cost by latent variables. Transp. Res. Part B Methodol. 2018, 117, 520-541. [CrossRef]

11. Díaz, F.; Cantillo, V.; Arellana, J.; de Dios Ortúzar, J. Accounting for stochastic variables in discrete choice models. Transp. Res. Part B Methodol. 2015, 78, 222-237. [CrossRef]

12. Jackson, W.B.; Jucker, J.V. An empirical study of travel time variability and travel choice behavior. Transp. Sci. 1982, 16, 460-475. [CrossRef]

13. Daly, A.; Ortuzar, J.D. Forecasting and data aggregation: Theory and practice. Traffic Eng. Control 1990, 31, 632-643.

14. Arellana, J.; Daly, A.; Hess, S.; de Dios Ortúzar, J.; Rizzi, L.I. Development of Surveys for Study of Departure Time Choice: Two-Stage Approach to Efficient Design. Transp. Res. Rec. 2012, 2303, 9-18. [CrossRef] 
15. Cirillo, C.; Maness, M.; Serulle, N.U. Measuring value of travel time and travel time variability in the presence of managed lanes: Results from a pilot stated preference survey on the Capital Beltway. Transp. Lett. 2014, 6, 23-35. [CrossRef]

16. Yildirimoglu, M.; Kahraman, O. Searching for empirical evidence on traffic equilibrium. PLoS ONE 2018, 13, e0196997. [CrossRef] [PubMed]

17. Tang, W.; Levinson, D.M. Deviation between Actual and Shortest Travel Time Paths for Commuters. J. Transp. Eng. Part A Syst. 2018, 144, 04018042. [CrossRef]

18. Zhu, S.; Levinson, D. Do people use the shortest path? An empirical test of Wardrop's first principle. PLOS ONE 2015, 10, e0134322. [CrossRef]

19. Parthasarathi, P.; Hochmair, H.; Levinson, D. Network structure and spatial separation. Environ. Plan. B Plan. Des. 2012, 39, 137-154. [CrossRef]

20. Parthasarathi, P.; Levinson, D.; Hochmair, H. Network structure and travel time perception. PLoS ONE 2013, 8, e77718. [CrossRef]

21. Carrion, C.; Levinson, D. A Model of Bridge Choice Across the Mississippi River in Minneapolis. In Network Reliability in Practice: Selected Papers from the Fourth International Symposium on Transportation Network Reliability; Levinson, D., Liu, H., Bell, M., Eds.; Springer: Berlin/Heidelberg, Germany, 2012; Chapter 8, pp. 115-129.

22. Zhu, S. The Roads Taken: Theory and Evidence on Route Choice in the Wake of the I-35W Mississippi River Bridge Collapse and Reconstruction. Ph.D. Thesis, University of Minnesota, Minnesota, MN, USA, 2010.

23. Zakay, D. On prospective time estimation, time relevance and temporal uncertainty. In Time, Cognition and Action; Macar, F., Poutas, I., Friedman, W., Eds.; Kluwer Academic: Dordrecht, The Netherlands, 1992; pp. 109-119.

24. Block, R.; Zakay, D. Models of psychological time revisited. In Time and Mind; Helfrich, H., Ed.; Hogrefe and Huber: Boston, MA, USA, 1996; pp. 171-195.

25. Angrilli, A.; Cherubini, P.; Pavese, A.; Manfredini, S. The influence of affective factors on time perception. Percept. Psychophys. 1997, 59, 972-982. [CrossRef]

26. Langer, J.; Wapner, S.; Werner, H. The effect of danger upon the experience of time. Am. J. Psychol. 1961, 74, 94-97. [CrossRef] [PubMed]

27. Thayer, S.; Schiff, W. Eye-contact, facial expression, and the experience of time. J. Soc. Psychol. 1975, 95, 117-124. [CrossRef] [PubMed]

28. Schachter, S.; Singer, J. Cognitive, social, and physiological determinants of emotional state. Psychol. Rev. 1962, 69, 379-399. [CrossRef] [PubMed]

29. Fox, R.; Bradbury, P.; Hampton, I. Time judgment and body temperature. J. Exp. Psychol. 1967, 75, 88-96. [CrossRef]

30. Tipples, J. Time flies when we read taboo words. Psychon. Bull. Rev. 2010, 17, 563-568. [CrossRef] [PubMed]

31. Thomas, E.; Weaver, W. Cognitive processing and time perception. Percept. Psychophys. 1975, 17, $363-367$. [CrossRef]

32. Jones, M.; Boltz, M. Dynamic attending and responses to time. Psychol. Rev. 1989, 96, 459-491. [CrossRef]

33. Boltz, M. Time estimation and expectancies. Mem. Cognit. 1993, 21, 853-863. [CrossRef]

34. Glicksohn, J.; Mourad, B.; Pavell, E. Imagination, absorption and subjective time estimation. Imagin. Cognit. Personal. 1991, 11, 167-176. [CrossRef]

35. Tellegen, A.; Atkinson, G. Openness to absorbing and self-altering experiences ("absorption"), a trait related to hypnotic susceptibility. J. Abnorm. Psychol. 1974, 83, 268-277. [CrossRef]

36. Madalina, S. Cognitive Mechanisms Involved in the Subjective Time Perception. Ph.D. Thesis, Babes-Bolyai University, Cluj-Napoca, Romania, 2011.

37. Peer, S.; Koster, P.; Verhoef, E. The perception of travel time variability. In Proceedings of the 4th International Symposium on Tranportation Network Reliability, Minneapolis, MN, USA, 22-23 July 2010.

38. Carrion, C.; Levinson, D. Uncovering the influence of commuters' perception on the reliability ratio. Transp. Find. 2019. [CrossRef]

39. Parthasarathi, P. Network Structure and Travel. Ph.D. Thesis, University of Minnesota, Minnesota, MN, USA, 2011.

40. Parthasarathi, P.; Levinson, D.; Hochmair, H. Network Structure and Travel Time Perception. In Proceedings of the International Association of Travel Behavior Research Conference, Toronto, ON, Canada, 15-19 July 2012. 
41. TBI. 2000 Travel Behavior Inventory Home Interview Survey: Data and Methodology; Metropolitan Council of the Twin Cities Area: St. Paul, MN, USA, 2003.

42. Zhu, S.; Levinson, D.; Liu, H.; Harder, K. The traffic and behavioral effects of the I-35W Mississippi River Bridge Collapse. Transp. Res. Part A 2010, 44, 771-784. [CrossRef]

43. Xie, F.; Levinson, D. Measuring the Structure of Road Networks. Geogr. Anal. 2007, 39, 336-356. [CrossRef]

44. Baldauf, D.; Burgard, E.; Wittmann, M. Time perception as a workload measure in simulated car driving. Appl. Ergon. 2009, 40, 929-935. [CrossRef] [PubMed]

45. Block, R.A.; Hancock, P.A.; Zakay, D. How cognitive load affects duration judgments: A meta-analytic review. Acta Psychol. 2010, 134, 330-343. [CrossRef] [PubMed]

46. Carrion, C. Travel Time Perception Errors: Causes and Consequences. Ph.D. Thesis, University of Minnesota, Minnesota, MN, USA, 2013.

47. Census (2006-2008) American Community Survey 3-Year Estimates, Minneapolis-St. Paul-Bloomington, MN-WI Metropolitan Statistical Area. Available online: http://factfinder.census.gov/ (accessed on 25 November 2009).

48. Vierordt, K. Der Zeitsinn nach Versuchen; H Laupp.: Tubingen, Germany, 1868.

49. Cameron, A.C.; Trivedi, P.K. Microeconometrics: Methods and Applications; Cambridge University Press: Cambridge, UK, 2005.

50. Wooldridge, J. Econometric Analysis of Cross Section and Panel Data, 2nd ed.; MIT Press: London, UK, 2010.

51. Johnston, J.; DiNardo, J. Econometric Methods; McGraw-Hill: New York, NY, USA, 1997.

52. Greene, W. Econometric Analysis, 7th ed.; Prentice-Hall: Upper Saddle River, NJ, USA, 2012.

53. Cramer, J. Econometric Applications of Maximum Likelihood Methods; Cambridge University Press: Cambridge, UK, 1986.

(C) 2019 by the authors. Licensee MDPI, Basel, Switzerland. This article is an open access article distributed under the terms and conditions of the Creative Commons Attribution (CC BY) license (http://creativecommons.org/licenses/by/4.0/). 